\title{
Fetus Small for Gestational Age
}

National Cancer Institute

\section{Source}

National Cancer Institute. Fetus Small for Gestational Age. NCI Thesaurus. Code

C114875.

A fetus that does not grow beyond the 10th percentile of conventionally accepted weight for gestational age. 